\title{
Multimedia education to support management of type 2 diabetes patients. A quasi-experimental study
}

\section{La educación multimedia como apoyo en el manejo de pacientes con diabetes tipo 2. Estudio cuasi experimental}

\section{Ignacio Pineda-del Aguila, Lubia Velázquez-López, Ma Victoria Goycochea-Robles,} Fabiola Angulo-Angulo and Jorge Escobedo-de la Peña*

Clinical Epidemiology Research Unit, Hospital General Regional No. 1 Carlos Mac Gregor Sánchez Navarro, Instituto Mexicano del Seguro Social, Mexico City, Mexico

\begin{abstract}
Objective: To evaluate the efficacy of education through a multimedia information system, in controlling patients with type 2 diabetes. Methods: Randomized open clinical trial. The intervention group was trained to consult an educative multimediattool in the waiting room, which was developed according to the population characteristics and centered on monitoring indicators, information on type 2 diabetes and nutrition. Venous blood concentrations of glucose, glycated hemoglobin (HbA1c), triglycerides, total cholesterol, high-density lipoprotein cholesterol, and low-density lipoprotein cholesterol were measured. Paired $t$ Student was used to assess the effect of the intervention. Results: 2,334 patients were included, 958 in the intervention group and 1,376 in the control group. In the intervention group, an increase in HDL-c values was observed (from 40.45 to $47.40 \mathrm{mg} / \mathrm{dL}$; $p=0.001$ ) as well as a descent on triglycerides values (from 227.78 to $210.38 \mathrm{mg} / \mathrm{dL} ; p=0.001$ ). There was a reduction on triglycerides levels in the control group (from 232.64 to $210.84 \mathrm{mg} / \mathrm{dL} ; p=0.016$ ). There was a significative increase in total cholesterol values in both groups. There were no changes in the mean values of glucose and HbA1c after the intervention. Conclusion: Implementation of a multimedia information system improves HDL-c and triglycerides in patients with diabetes. There is a need for a continuous reinforcement of the educative intervention by health professionals to improve glycemic-and other indicators in metabolic control.
\end{abstract}

KEY WORDS: Multimedia. Type 2 diabetes. Prevention and control. Dyslipidemia. Cardiovascular risk factors.

\section{Resumen}

Objetivo: Evaluar la eficacia de la educación a través de un sistema de información multimedia en el control del paciente con diabetes tipo 2. Método: Ensayo clínico abierto aleatorizado. El grupo de intervención fue instruido para consultar una hêrramienta educativa multimedia en la sala de espera de los consultorios, misma que fue diseñada de acuerdo a las caractêristicas de la población y centrada en automonitoreo de indicadores, información sobre diabetes tipo 2 y nutrición. Se midieron en sangre venosa las concentraciones de glucosa, hemoglobina glucosilada $(\mathrm{HbA1c})$, triglicéridos, colesterol total, colesterol ligado a lipoproteínas de alta densidad (HDL-c) y colesterol ligado a lipoproteínas de baja densidad. Con la $t$ de Studentpareada se evaluó el efecto de la intervención. Resultados: Se incluyeron 2334 pacientes, 958 en el grupo de intervención y 1376 en el grupo control. Se observó en el grupo de intervención un incremento del HDL-c (de 40.45 a $47.40 \mathrm{mg} / \mathrm{dl} ; \mathrm{p}=0.001)$ y una disminución de los triglicéridos (de 227.78 a $210.38 \mathrm{mg} / \mathrm{dl} ; p=0.001$ ). En el grupo control disminuyeron los triglicéridos (de 232.64 a $210.84 \mathrm{mg} / \mathrm{dl} ; p=0.016$ ). En ambos grupos se incrementó de forma significativa el colesterol total. No se-observaron cambios en los valores de glucosa y HbA1c posterior a la intervención. Conclusión: La implementación de un

\section{Correspondence:}

*Jorge Escobedo de la Peña

Av. Gabriel Mancera 222,

C.P.03100, Mexico City, Mexico

E-mail: jorgeep.@unam.mx
Date of reception: 28-01-2018

Date of acceptance: 19-05-2018

DOI: $10.24875 / C I R U E . M 18000061$
Cir Cir. 2018;86:354-360

Contents available at PubMed www.cirugiaycirujanos.com 
sistema de información multimedia mejora el HDL-c y los triglicéridos del paciente con diabetes. Se requiere un reforzamiento continuo de la intervención educativa por parte del profesional de la salud para incidir en el control glucémico y otros indicadores del control metabólico.

PALABRAS CLAVE: Multimedia. Diabetes tipo 2. Prevención y control. Dislipidemia. Factores de riesgo cardiovascular

\section{Introduction}

Comprehensive treatment of type 2 diabetes includes a lifestyle modification, coupled with adherence to drug treatment and general measures of care, where education for self-management of the disease plays an important role ${ }^{1,2}$. Education is a necessary element for the proper management of diabetes, and it is required that all patients receive education and support to promote self-management ${ }^{3}$.

A reduction of $0.88 \%$ in glycated hemoglobin (HbA1c) has been reported when education for diabetes self-management is implemented in adults, including individual, and group education, combination of modalities and education provided by remote means, such as online and telephone communication ${ }^{4}$. The purpose of diabetes education is to provide knowledge, develop skills and learning to make correct decisions for a healthy lifestyle, as well as to promote active participation with the health professional ${ }^{5,6}$.

In recent years, information and communication technologies (ICT) have shown a promising effect owing the ease they offer to spread knowledge on diabetes, prevent complications ${ }^{7}$ and reduce costs $^{8}$, both in prevention and treatment ${ }^{9,10}$ and in education on the disease ${ }^{11-13}$. ICTs have even achieved a positive effect on the emotional aspect of the patient with type 2 diabetes $^{14}$.

Even so, the use of ICTs is controversial in terms of the long-term effect on disease control. However, a reduction in $\mathrm{HbA} 1 \mathrm{c}$ has been reported after an intervention with $I C T^{15,16}$.

The purpose of this study was to assess the efficacy of education through a multimedia information system for glycemic and lipid profile control in patients with type 2 diabetes.

\section{Method}

A quasi-experimental 24-month follow-up study was conducted in an adult population diagnosed with type 2 diabetes in a family medicine unit (FMU) of the Mexican Institute of Social Security, in Mexico City, which has thirteen family medicine offices. Approval was obtained from of the Institute's research and ethics committee. Patients who agreed to participate in the study signed the informed consent letter once they were explained the risks and benefits involved.

Patients diagnosed with diabetes by their attending physician, who knew how to read or write, who had no hearing problems or complications that prevented them from consulting the multimedia information system called DM2 Monitor were included (Fig. 1).

Seven offices (out of thirteen) were randomly chosen for the DM2 Monitor-exposure group and the remaining six offices in the unit continued with usual medical care (control group). In both groups, glucose, $\mathrm{HbÂ} 1 \mathrm{c}$, triglycerides, total cholesterol, high-density lipoprotein cholesterol (HDL-C) and low-density lipoprotein cholesterol (LDL-C) concentrations were measured invenous blood after ten hours of fasting at the beginning and at the end of the study.

\section{Characteristics of the maneuver}

The DM2 Monitor design was user-centered, based on previously-identified population characteristics, such as gender, level of education and age. The platform was designed to be used through touchsceen monitors, with augmented typography and with a ticket printer to print the information of the graphs of the metabolic control indicator values sequence in time at their different visits, the list of food and the menuthat was designed by the patient in the system.

The DM2 Monitor contents were based on the theory of self-management of chronic illness. In order to drive the patients into action in the care of the disease, video capsules and animated materials were created, in addition to the equivalent food exchange system simulator, by means of which the patients Ereated their own personalized menus.

Patients were also encouraged to participate in the control of the disease and in decision making by identifying the results of their main control indicators ( $\mathrm{HbA1c}$, glucose, lipid profile) in a timeline, and reach an agreement with the doctor on the actions to be followed in the care of their disease. DM2 Monitor had audio devices for the reproduction of informative capsules. The patient could enter the system as many times as he/she considered relevant. 


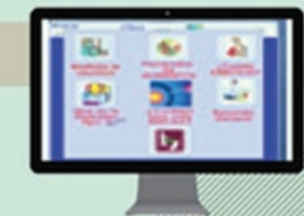

Multimedia information system

DM 2 MONITOR

Modules Description

\section{METABOLIC CONTROL INDICATORS}

Module designed to consult the evolution or behavior of a specific indicator through time series graphs.

Video-clips were included to present the definition and explanation of the indicator and its control goal, as well as the interpretation of the graph.

According to ADA, indicators and their control goals were: glucose $(90-130 \mathrm{mg} / \mathrm{dL})$, $\mathrm{HbA} 1 \mathrm{c}(>7.0 \%)$, triglycerides $(<150 \mathrm{mg} / \mathrm{dL})$, total cholesterol, HDL-C (), and LDL-C $(<100 \mathrm{mg} / \mathrm{dL})$.

\section{INFORMATION ON TYPE 2 DIABETES}

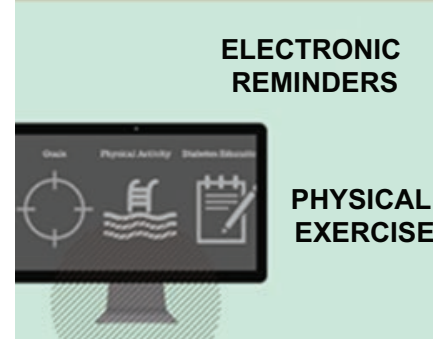

TYPE 2 DIABETES AND ITS COMPLICATIONS
According to ADA criteria, an electronic reminder was designed with the recommended figures for each metabolic control indicator and the printing option was always available.

Animated materials with relevant information on types of physical activity recommended for people with type 2 diabetes, the recommended duration and intensity as well as precautions

Material animated with the Flash $\circledast$ technique present common complications in order to raise awareness and take preventive actions. Key concepts about DM2 were also represented, such as: the causes of type 2 diabetes, high and low sugar, the importance of a balanced diet, among others.

\section{EQUIVALENT FOOD EXCHANGE SYSTEM SIMULATOR}

Based on the Official Mexican Standard, the simulator of the Mexican equivalent food exchange system was designed for the creation of menus, taking into account age, gender, and current weight at the time. This way, the user was able to create virtual menus with the selection of the best preferred food equivalent of each food group; through alerts, the system prevents choosing more than one food of the same group, the number of allowed servings; in addition, it presents to the user finally selected foods' individual and total calories per group and in general. This module was supervised by a certified Nutritionist.

Figure 1. Description of DM2 Monitor contents.

\section{DM2 Monitor description}

DM2 Monitor was developed with three purposes: 1) to promote self-monitoring by each patient included in the study by showing him/her his/her biochemical data recorded at the FMU; 2) to provide the patient with information on type 2 diabetes, with visual and auditory means through materials animated with the Flash ${ }^{\circledast}$ technique being used for this purpose; and 3) to promote adherence to the diet with a module for the creation of a healthy menu, following the Mexican equivalent food exchange system ${ }^{17}$ (Fig. 2).
Seven computer kiosks (one for each intervention group office) with touch screen monitors, with audio devices and ticket printer were installed at the offices' 'waiting room, to consult the educational tool. The doctors of the exposed group offices were responsible for referring patients to the DM2 Monitor. Patients were instructed by two nursing professionals on the use of DM2 Monitor. Each patient was registered in the system.

Access to DM2 Monitor was maintained for a 24-month period and its use was free for previously registered patients, who were invited to go and check it at each appointment with their family doctor. During the study follow-up period, a nurse was in charge of 


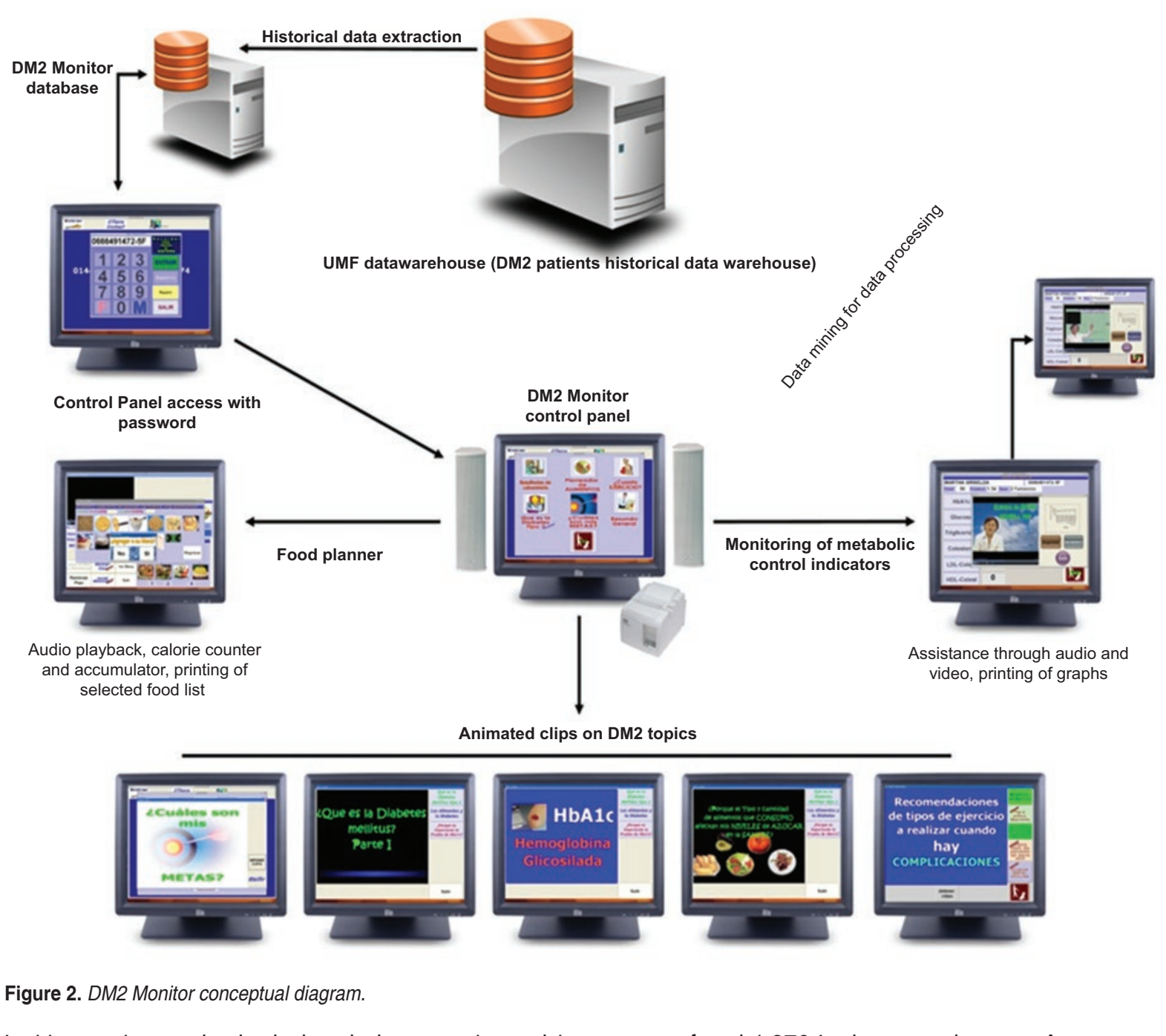

inviting patients who had already been registered in order to encourage the use of the educational tool.

\section{Data analysis}

Patient baseline characteristics were analyzed by estimating central tendency and dispersion measures (mean and standard deviation) and proportions. To measure the effect of the intervention on metabolic control indicators ( $\mathrm{HbA} 1 \mathrm{c}$, triglycerides, total cholesterol, fasting glucose, HDL-C and LDL-C), Student's t-test was used for independent samples at baseline and the paired t-test was used to compare the effect at the end of the intervention. Statistical analysis was performed with the SPSS software, ver. 22.

\section{Results}

Baseline data are shown in table 1. The sample comprised 2,334 patients, 958 in the intervention group of and 1,376 in the control group. Average age was similar $(61.5 \pm 12.2$ and $63.3 \pm 13.3$ years respectively), with a higher proportion of women in both groups (64.9 and $63.9 \%)$. Average body mass index in both groups it was higher than $30 \mathrm{~kg} / \mathrm{m}^{2}$; therefore, it can be claimed that, on average, the study population of diabetic patients suffers from obesity.

Table 2 shows the changes in metabolic controf indicators at each one of the groups. In the group with DM2 Monitor, HDL-C was significantly increased (from $40.45 \pm 10.03$ to $47.40 \pm 11.76 \mathrm{mg} / \mathrm{dL} ; p=0.001$ ) and a significant reduction was observed in triglycerides (from $227.78 \pm 132.99$ to $210.38 \pm 110.63 \mathrm{mg} / \mathrm{dL}$; $p=0.001)$. In both groups, total cholesterol was significantly increased, but while in the control group this increase was significant for both HCL-C and LDL- $\bar{C}$, in the intervention group only the increase in $\mathrm{HDL}-\mathrm{C}^{4}$ was significant, while LDL-C remained at similar values:

Glucose and $\mathrm{HbA} 1 \mathrm{C}$ remained without significant changes during follow-up in both groups. 
Table 1. Baseline characteristics and metabolic control in the population with type 2 diabetes

\begin{tabular}{lcc}
\hline & $\begin{array}{c}\text { DM2 Monitor group } \\
(\mathbf{n}=\mathbf{9 5 8})\end{array}$ & $\begin{array}{c}\text { Control group } \\
(\mathbf{n}=\mathbf{1 , 3 7 6})\end{array}$ \\
\hline Age (years) & $61.5 \pm 12.2$ & $63.3 \pm 13.3$ \\
Gender & & \\
Females & $614(64.9 \%)$ & $879(63.9 \%)$ \\
Males & $344(35.9 \%)$ & $497(36.1 \%)$ \\
Glucose $(\mathrm{mg} / \mathrm{dL})$ & $164.65 \pm 58.96$ & $165.81 \pm 60.17$ \\
HbA1c $(\%)$ & $8.84 \pm 2.07$ & $8.94 \pm 1.96$ \\
HDL-C (mg/dL) & $40.45 \pm 10.03$ & $44.07 \pm 7.78$ \\
LDL-C (mg/dL) & $127.21 \pm 34.16$ & $123.88 \pm 36.64$ \\
Triglycerides $(\mathrm{mg} / \mathrm{dL})$ & $227.78 \pm 132.99$ & $232.64 \pm 147.72$ \\
Total cholesterol $(\mathrm{mg} / \mathrm{dL})$ & $198.61 \pm 35.09$ & $200.97 \pm 36.62$ \\
\hline
\end{tabular}

Student's t-test, $p<0.05$ for HDL-C and LDL-C. Data expressed as averages \pm standard deviation. The comparisons were made with Student's t-test for paired samples. HbA1c: glycated hemoglobin; HDL-C: high-density lipoprotein cholesterol; LDL-C: low-density lipoprotein cholesterol.

\section{Discussion}

Type 2 diabetes is a disease that requires comprehensive treatment, where the changes the patient adopts by improving his/her lifestyle and care of the disease are substantial for an adequate management.

In the present study, an improvement was observed in HDL-C and triglycerides after 24 months of followup using an educational tool resorting to ICT. Similar data have been previously reported, although with a decrease in glucose and $\mathrm{HbA1c}$ values, with a multimedia educational tool and nutritional reinforcement ${ }^{15}$. Our results differ due the lack of an effect on HbA1c, which we consider might be due to reinforcement by a nutritionist in that study during follow-up with the educational tool. In this sense, it could be claimed that the use of ICT would have a greater benefit on metabolic control indicators if complemented with advice and reinforcement of the consultations made in the educational tool by the health professional. Nevertheless, other authors have not found benefit on $\mathrm{HbA1c}$ reduction, but they have found an increased perception of disease complications with a similar intervention to that of this study ${ }^{18}$.

It is important emphasizing that total cholesterol was increased in both groups. However, in the control group, the increase was in both LDL-C and HDL-C, whereas in the intervention group the increase was only favorable in HDL-C, while LDL-C remained stable. It is necessary for the medical professional to make use of educational strategies and constant surveillance in order to promote pharmacological treatment adherence according to the guidelines, with the purpose to reduce cardiovascular risk factors ${ }^{19}$.

There is limited information in Mexico about multimedia information systems implementation for patients with type 2 diabetes. This type of intervention aimed at providing education using ICTs has been promoted by different consensuses on the treatment of diabetes as a new effective tool for providing education ${ }^{20,21}$.

One relevant aspect of diabetes education lies inqaking patient age and level of education into account, particularly because technology may not be a useful tool if these characteristics are not considered. There is evidence that subjects with low levels of education have had a greater increase in knowledge on diabêtes after a multimedia education strategy; however, they learn less than those with higher levels of education 22 .

A greater impact on metabolic control has been reported with short exposure times and controlled environments, but educational intervention with the use. of ICTs in an autonomous way has been also confirmed to have less impact than when there is active participation of the doctor, the nurse, the nutritionist orthe diabetes educator ${ }^{23-25}$.

Strategies aimed at integrating digital information services should be designed based on a modef of chronic illness care, in order to promote active participation of the patient in the care of the disease, in addition to systematic, monitored and motivationaRadvice to the patient by the health professional ${ }^{26}$.

The intervention was aimed at implementing a multimedia information system within a medical care setting in a clinical unit in a context that was the closest to real and everyday practice. Even when the use of the tool was promoted, one possible limitation is the lack of reinforcement on the use of the educational tool at each visit. We consider that autonomous $>a d-$ ministration without constant reinforcement by the health professional might have been the limitation for observing an $\mathrm{HbA1c}$ reduction. It is highly probable that the population with diabetes requires constant support from the healthcare professional, just as other authors have identified in similar populations $s^{15,27}: \underline{\varrho}$

One relevant aspect of this study is the management of patient clinical data at the FMU, with the purpose for the technological tool to include clinical and epidemiological surveillance and patient awareness utilities. With this utility, the presence of the doctor or 


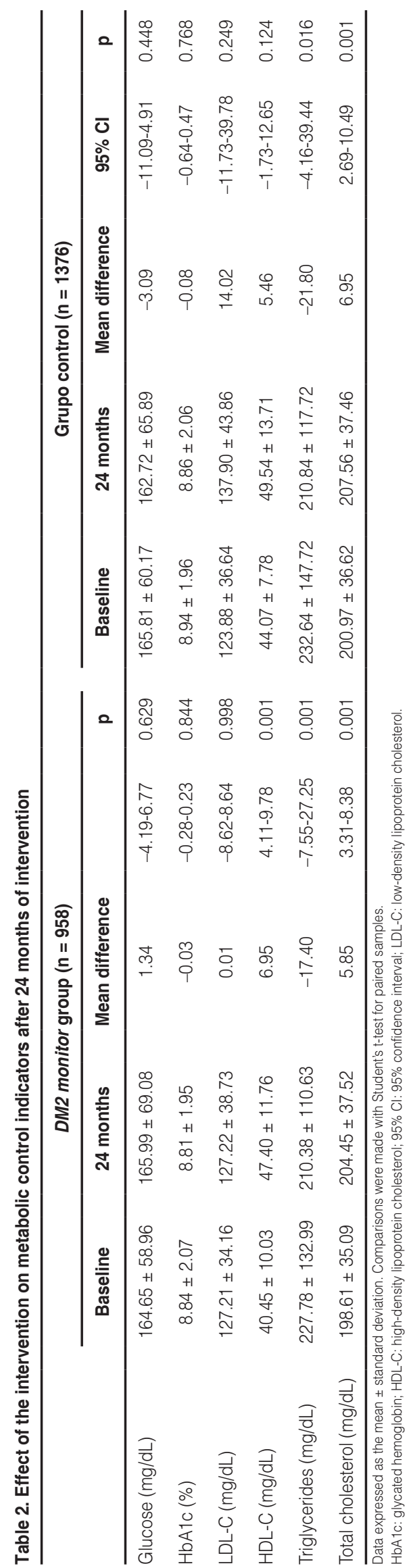

health professional in the doctor-educational toof-patient equation was sought. With the use of this strategy, reductions in $\mathrm{HbA} 1 \mathrm{c}$ values of up to $0.8 \%$ have been observed ${ }^{16}$.

The use and evaluation of ICTs in the promotion of health in the type 2 diabetes patient are limited. It is important to continue assessing this type of initiatives, in order for care to be unified and to make use of technological tools to support the health professional, and to contribute to a better communication between the patient and the health professionali $\overline{\mathbf{l o}_{2}^{2}, 29}$.

The strategies for the use of ICTs must be further developed and investigated in Latin America, targetting populations that suffer from chronic diseases and vulnerable groups, considering communication strategies and new forms of digital literacy, as well as the use of social networks according to these populations. Morreover, health promotion and education initiatives through ICTs should be part of health policies, given that there is an urgency related to limited access to health, owing to access inequities due to different factors, in addition to epidemiological transitions overlap and insufficiency of both human and economic resources ${ }^{30}$.

Initiatives through ICTs can be effective because they complete the circle of the doctor-patient care process. In addition, they contribute to real-timespatient monitoring with treatment goals customization through clinical data management and follow-up with personalized advice ${ }^{31,32}$.

It is important to consider that patients with diabetes who attend primary care FMUs still are at high risk of microvascular and macrovascular complications, since they present with obesity, metabolic lack of control and dyslipidemia. Comprehensive treatment is necessary in order to motivate patients to take care of their disease and achieve treatment goals ${ }^{33}$.

One limitation of this work is the lack of a record of the number of visits to DM2 Monitor, given that free access to it was indicated. Future investigations should consider the use of access metrics and establishing an association with optimal exposure time or a performance indicator.

Finally, it is important to consider that this type of educational strategies using ITCs can promote the development of effective service models in order to improve the care of chronic illnesses, with positive results being obtained both in the improvement of metabolic control indicators and in knowledge and motivation of the patient with diabetes ${ }^{34}$. However, their long-term effects have not been properly measured. Nevertheless, strategies as the one herein 
presented contribute to improve control in the patient with type 2 diabetes.

\section{Conclusion}

It is important to continue assessing studies in patients with type 2 diabetes aimed at using ICTs to provide education in different modalities, which should be a complement to the guidance received from the medical and nutritional professional.

Implementation of a multimedia information system to provide diabetes education can improve the lipid profile in patients with type 2 diabetes. However, participation of the health professional is required, so that that the application of knowledge acquired through a technological tool is promoted in order to impact on metabolic control.

\section{Funding}

This study received funding granted by the Mexican Institute of Social Security, registration number 2006/1B/004 FIS/IMSS/PROT/143, in the 2006 call for Strategic Projects in Health and Technological Development.

\section{Conflicts of interests}

The authors declare that they have no conflicts of interest.

\section{References}

1. American Diabetes Association. Foundations of care: education, nutrition, physical activity, smoking cessation, psychosocial care, and immunization. Sec. 4. In Standards of Medical Care in Diabetes - 2015. Diabetes Care. 2015;38(Suppl. 1):S20-S30.

2. Garber AJ, Abrahamson MJ, Barzilay JI, Blonde L, Bloomgardenet ZT, Bush MA, et al. AACE comprehensive diabetes management algorithm 2013. Endocr Pract. 2013;19:327-36.

3. American Diabetes Association. Standards of medical care in diabetes - 2018. Diabetes Care. 2018;40(Suppl 1):S38-S50.

4. Chrvala CA, Sherr D, Lipman RD. Diabetes self-management education for adults with type 2 diabetes mellitus: a systematic review of the effect on glycemic control. Patient Educ Couns. 2016;99:926-43.

5. Funnell, MM, Anderson, RM, Arnold MS, Barr PA, Donnelly MB, Johnson PD, et al. Empowerment: an idea whose time has come in diabetes education. Diabetes Educ. 1991;17:37-41.

6. Haas L, Maryniuk M, Beck J, Cox CE, Duker P, Edwards L, et al. National standards for diabetes self-management education and support. Diabetes Care. 2012;35:2393-401.

7. Wyne K. Information technology for the treatment of diabetes: improving outcomes and controlling costs. J Manag Care Pharm. 2008;14(2 Su$\mathrm{ppl}):$ S12-S17.

8. Davis BU. Benefits of information technology - enabled diabetes management. Diabetes Care. 2007;30:1137-42.

9. Kaufman N. Information technology in the service of diabetes prevention and treatment. Int J Clin Pract. 2011;65:47-54.

10. Hunt JS, Siemienczuk J, Gillanders W, LeBlanc BH, Rozenfeld Y, Bo$\operatorname{nin} \mathrm{K}$, et al. The impact of a physician-directed health information technology system on diabetes outcomes in primary care: a pre- and post-implementation study. Inform Prim Care. 2009;17:165-74.
11. Kandula NR, Nsiah-Kumi PA, Makoul G, Sager J, Zei CP, Glass S, et al. The relationship between health literacy and knowledge improvement after a multimedia type 2 diabetes education program. Patient Educ Couns. 2009;75:321-7.

12. Boren SA, Gunlock TL, Peeples MM, Krishna S. Computerized learning technologies for diabetes: a systematic review. J Diabetes Sci Technol. 2008;2:139-46.

13. Nundy S, Lu CYE, Hogan $P$, Mishra A, Peek ME. Using patient-generated health data from mobile technologies for diabetes self-management support: provider perspectives from an academic medical center. J Diabetes Sci Technol. 2014;8:74-82.

14. Hadjiconstantinou M, Byrne J, Bodicoat DH, Robertson N, Eborall H, Khunti K, et al. Do web-based interventions improve well-being in type 2 diabétes? A systematic review and meta-analysis. J Med Internet Res. 2016;18:e270.

15. Velázquez-López L, Muñoz-Torres AV, Medina-Bravo P, Vilchis-Gil J Kllnder-Klander M, Escobedo-de la Peña J. Multimedia education program and nutrition therapy improves $\mathrm{HbA1c}$, weight, and lipid profile of patients with type 2 diabetes: a randomized clinical trial. Endocrine. 2017;58:236-45.

16. Jethwani K, Ling E, Mohammed M, Myint-U K, Pelletier A, Kvedar JC. Diabetes connect: an evaluation of patient adoption and engagement in a web-based remote glucose monitoring program. J Diabetes SciTechnol. 2012:6:1328-36.

17. Pérez Lizaur AB, Marván LL. Sistema mexicano de alimentos equivalentes. Fomento de Nutrición y Salud, AC. 4. a ed. México; 2014.

18. Gerber BS, Brodsky IG, Lawless KA, Smolin LI, Arozullah AM, Smith EV, et al. Implementation and evaluation of a low-literacy diabetes education computer multimedia application. Diabetes Care. 2005;28:1574-80.

19. Chamberlain JJ, Herman WH, Leal S, Rhinehart AS, Shubrook JH, Skolnik N, et al. Pharmacologic therapy for type 2 diabetes: synopsis of the 2017 American Diabetes Association standards of medical care in diabetes. Ann Intern Med. 2017;166:572-8.

20. Powers, MA, Bardsley J, Cypress M, Duker P, Funnell MM, Fischt AH, et al. Diabetes self-management education and support in type 2 diabetes: a joint position statement of the American Diabetes Association, the American Association of Diabetes Educators, and the Academy of Dutrition and Dietetics. J Acad Nutr Diet. 2015;115:1323-34.

21. Arnhold M, Quade M, Kirch W. Mobile applications for diabetics: ¿systematic review and expert-based usability evaluation considering the special requirements of diabetes patients age 50 years or older. FMed Internet Res. 2014;16:e104.

22. Kandula NR, Nsiah-Kumi PA, Makoul G, Sager J, Zei CP, Glass S, et al. The relationship between health literacy and knowledge improvement after a multimedia type 2 diabetes education program. Patient Educ Couns. 2009;75:321-7.

23. Kelders SM, Kok RN, Ossebaard HC, Van Gemert-Pijnen JE. Persuasive system design does matter: a systematic review of adherence to web-based interventions. J Med Internet Res. 2012;14:e152.

24. Mohr DC, Cuijpers P, Lehman K. Supportive accountability: a model for providing human support to enhance adherence to eHealth interventions. J Med Internet Res. 2011:13:e30.

25. Spring B, Duncan JM, Janke EA, Kozak AT, McFadden HG, DeMott A, et al. Integrating technology into standard weight loss treatment: a randomized controlled trial. JAMA Intern Med. 2013;173:105-11.

26. Beck J, Greenwood DA, Blanton L, Bollinger ST, Butcher MK, Condon JE, et al. 2017 National standards for diabetes self-management education and support. Diabetes Care. 2017;40:1409-19.

27. Rollo ME, Aguiar EJ, Williams RL, Wynne K, Kriss M, Callister R, et al. eHealth technologies to support nutrition and physical activity behaviors in diabetes self-management. Diabetes Metab Syndr Obes. 2016;4:381-90.

28. Khansa L, Davis Z, Davis H, Chin A, Irvine H, Nichols L, et al. Health information technologies for patients with diabetes. Technology in Society. 2016;44:1-9.

29. David SK, Rafiullah MRM. Innovative health informatics as an effective modern strategy in diabetes management: a critical review. Int $\Phi$ Clin Pract. 2016;70:434-49.

30. Oviedo E, Fernández A. Tecnologías de la información y la comuniçâción en el sector salud: oportunidades y desafíos para reducir inequidades en América Latina y el Caribe. CEPAL - Serie Políticas Sociales No. 165. Santiago de Chile; 2010.

31. Jimison $H$, Gorman $P$, Woods $S$, Nygren P, Walker M, Norris S, èt al. Barriers and drivers of health information technology use for the elderly, chronically ill, and underserved. Evidence Report/Technology Assessment No. 175 (Prepared by the Oregon Evidence-based Practice Genter under Contract No. 290-02-0024). AHRQ Publication No. 09-E004_Rockville, MD: Agency for Healthcare Research and Quality; November2008.

32. Didarloo A, Shojaeizadeh D, Alizadeh M. Impact of educational intervention based on interactive approaches on beliefs, behavior, hemoglobin A1c, and quality of life in diabetic women. Int J Prev Med. 2016;7:38.

33. Gazzaruso C, Fodaro M, Coppola A. Structured therapeutic education in diabetes: is it time to re-write the chapter on the prevention of diabetic complications? Endocrine. 2016;53:347-9.

34. Bauer AM, Thielke SM, Katon W, Unützer J, Areán P. Aligning health information technologies with effective service delivery models to improve chronic disease care. Prev Med. 2014;66:167-72. 